\title{
Cell surface-expressed phosphatidylserine as therapeutic target to enhance phagocytosis of apoptotic cells
}

\author{
K Schutters ${ }^{1}$, DHM Kusters ${ }^{1}$, MLL Chatrou ${ }^{1}$, T Montero-Melendez ${ }^{2}$, M Donners ${ }^{3}$, NM Deckers ${ }^{1}$, DV Krysko ${ }^{4,5}$, P Vandenabeele ${ }^{4,5}$, \\ M Perretti ${ }^{2}$, LJ Schurgers ${ }^{1}$ and CPM Reutelingsperger ${ }^{*, 1}$
}

Impaired efferocytosis has been shown to be associated with, and even to contribute to progression of, chronic inflammatory diseases such as atherosclerosis. Enhancing efferocytosis has been proposed as strategy to treat diseases involving inflammation. Here we present the strategy to increase 'eat me' signals on the surface of apoptotic cells by targeting cell surfaceexpressed phosphatidylserine (PS) with a variant of annexin A5 (Arg-Gly-Asp-annexin A5, RGD-anxA5) that has gained the function to interact with $\alpha_{v} \beta_{3}$ receptors of the phagocyte. We describe design and characterization of RGD-anXA5 and show that introduction of RGD transforms anxA5 from an inhibitor into a stimulator of efferocytosis. RGD-anxA5 enhances engulfment of apoptotic cells by phorbol-12-myristate-13-acetate-stimulated THP-1 (human acute monocytic leukemia cell line) cells in vitro and resident peritoneal mouse macrophages in vivo. In addition, RGD-anxA5 augments secretion of interleukin-10 during efferocytosis in vivo, thereby possibly adding to an anti-inflammatory environment. We conclude that targeting cell surfaceexpressed PS is an attractive strategy for treatment of inflammatory diseases and that the rationally designed RGD-anXA5 is a promising therapeutic agent.

Cell Death and Differentiation (2013) 20, 49-56; doi:10.1038/cdd.2012.107; published online 7 September 2012

Efferocytosis, the phagocytosis of apoptotic cells, proceeds rapidly and efficiently in healthy tissues. ${ }^{1}$ It is of great importance to tissue homeostasis as it prevents leakage of potentially cytotoxic or antigenic contents into the extracellular environment, which would initiate inflammation and might cause tissue injury, and it counteracts inflammation by secretion of anti-inflammatory cytokines. ${ }^{2}$ Diseased tissues are characterized by a sustained presence of dead cells due to an imbalance between apoptosis and phagocytosis. Impaired efferocytosis has been demonstrated to contribute to progression of chronic inflammatory diseases such as atherosclerosis ${ }^{3}$ and systemic lupus erythematosus. ${ }^{4}$ Enhancing efferocytosis has been proposed as strategy to treat chronic inflammation. ${ }^{4-6}$

Efferocytosis depends on recognition of the apoptotic cell by the phagocyte. Different 'eat me' signals on the apoptotic cell surface, also called ACAMP (apoptotic cell-associated molecular patterns), have been identified. ${ }^{7}$ Cell surfaceexpressed phosphatidylserine (PS) is the best characterized and one of the most important 'eat me' signals for efferocytosis. $^{8,9}$ PS binds directly to a phagocyte receptor or via bridging molecules including growth arrest-specific 6 , milk fat globule-epidermal growth factor 8 (MFG-E8) and annexin $\mathrm{A} 1 .^{9}$

Annexin A5 (anxA5), a structurally and biophysically wellcharacterized member of the annexin multigene family, binds to PS with high affinity in a $\mathrm{Ca}^{2+}$-dependent manner. ${ }^{10}$ It is used broadly as molecular imaging agent to measure apoptosis in vitro ${ }^{11}$ and in vivo in animal models and patients. ${ }^{10}$ AnxA5 does not act as a bridging molecule but inhibits efferocytosis by shielding the PS-expressing surface of apoptotic cells. ${ }^{12,13}$ The molecular imaging experience with anxA5 triggered us to explore whether anxA5 could be transformed into a therapeutic agent enhancing efferocytosis. It has been shown that the PS receptor TIM-4 (T-cell immunoglobulin- and mucin-domain-containing molecule-4) and integrin $\alpha_{v} \beta_{3 / 5}$ act cooperatively during efferocytosis. ${ }^{14}$ Here we report the transformation of anxA5 from an inhibitory into a stimulatory protein of efferocytosis by introduction of an Arg-Gly-Asp (RGD) motif into its N-terminal tail, which is located apical to the PS-binding sites. We show that RGDanxA5 interacts with $\alpha_{v} \beta_{3 / 5}$ on the phagocyte, stimulates

\footnotetext{
${ }^{1}$ Department of Biochemistry, Cardiovascular Research Institute Maastricht, University of Maastricht, Maastricht $6200 \mathrm{MD}$, The Netherlands; ${ }^{2}$ William Harvey Research Institute and The London School of Medicine, Queen Mary University of London, London, UK; ${ }^{3}$ Department of Molecular Genetics, University of Maastricht, Maastricht, The Netherlands; ${ }^{4}$ Department of Biomedical Molecular Biology, Ghent University, Ghent, Belgium and ${ }^{5}$ Molecular Signaling and Cell Death Unit, Department for Molecular Biomedical Research, VIB, Ghent, Belgium

${ }^{*}$ Corresponding author: CPM Reutelingsperger, Department of Biochemistry, Cardiovascular Research Institute Maastricht, University of Maastricht, PO Box 616, Maastricht 6200 MD, The Netherlands. Tel: + 3143 3881533; Fax: + 3143 3884159; E-mail: c.reutelingsperger@ maastrichtuniversity.nl

Keywords: apoptosis; efferocytosis; phosphatidylserine; annexin A5

Abbreviations: cRGD, cyclic Arg-Gly-Asp; EDTA, ethylenediaminetetraacetic acid; EGTA, ethylene glycol tetraacetic acid; IL-10, interleukin-10; MALDI-TOF/TOF, matrix-assisted laser desorption/ionization-time of flight/time of flight; MFG-E8, milk fat globule-epidermal growth factor 8; PMA, phorbol-12-myristate-13-acetate; PS, phosphatidylserine; RGD-anxA5, Arg-Gly-Asp-annexin A5; RGT-anxA5, Arg-Gly-Thr-annexin A5; THP-1, human acute monocytic leukemia cell line; TIM-4, T-cell immunoglobulin- and mucin-domain-containing molecule-4; TNF $\alpha$, tumor necrosis factor $\alpha$

Received 05.4.12; revised 09.7.12; accepted 23.7.12; Edited by M Piacentini; published online 07.9.12
} 


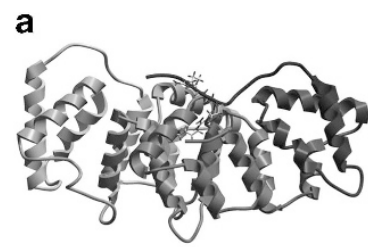

b

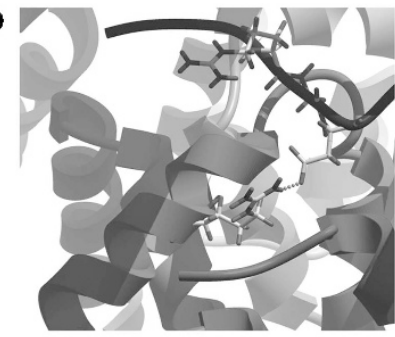

C

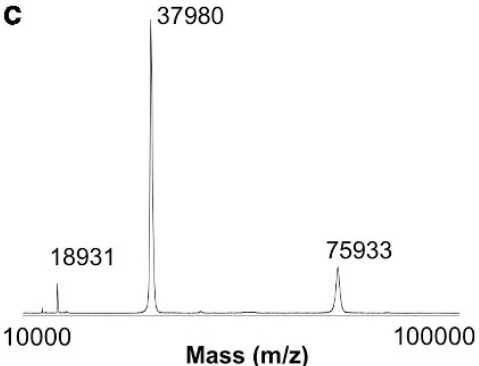

d

\begin{tabular}{|c|c|}
\hline Variant & Amino-acid-replacements \\
\hline RGT - anxA5 & G166C, C316S \\
\hline RGD - anxA5 & T8D, G166C,C316S \\
\hline RGD - M1234 & T8D, E72D, D144N, E228A, D303N \\
\hline
\end{tabular}

Figure 1 (a) The ribbon structure is given for human anxA5, colored from $\mathrm{N}$ to $\mathrm{C}$ terminus following blue-to-red standard coloring. The wild-type sequence from human anXA5 (PDB accession number 1anw.pdb) was mutated in silico by the introduction of a Thr8Asp missense mutation after which the structure was regularized and minimized using the ICM Promolecular modeling package (Molsoft LLC). In this minimized structure Asp8 is involved in hydrogen bonding to Arg 285, which may help in stabilization of the $\mathrm{N}$ terminus. The side chains are indicated for the RGD motif. (b) The interaction between Asp 8 and Arg 285 is shown in detail. (c) MALDI-TOF/TOF analysis of a representative batch of purified RGD-anxA5 showing monomer (37980 Da), the bis-protonated monomer (18931 Da) and the dimer $(75933 \mathrm{Da})$. (d) anxA5 variants and their modifications, all variants are extended with an $\mathrm{N}$-terminal histidine tag

efferocytosis in vitro and in vivo and enhances anti-inflammatory cytokine production. We conclude that RGD-anxA5 is a promising strategy for treatment of diseases with impaired efferocytosis.

\section{Results}

PS-binding in vitro. First we investigated effects of mutation on PS-binding properties in vitro. RGD-anxA5 exhibited $\mathrm{Ca}^{2+}$-dependent PS-binding similar to RGT-anxA5 (ArgGly-Thr-annexin A5), while RGD-M1234, which is an anxA5 variant lacking functional $\mathrm{Ca}^{2+} / \mathrm{PS}$-binding sites, ${ }^{15}$ showed no phospholipid-binding activity (Figure 2a). The $\mathrm{Ca}^{2+}$. sensitivity of PS-binding was not changed by the introduction of RGD into anxA5's N-terminal tail (Figure 2b). In order to assess binding to apoptotic cells by flow cytometry, RGTanxA5 and RGD-anxA5 were labeled with fluorescein, which yielded 1:1 stoichiometric complexes as determined by matrix-assisted laser desorption/ionization-time of flight/time of flight (MALDI-TOF/TOF; data not shown). RGD-anxA5 and RGT-anxA5 show comparable dose-response curves for binding apoptotic cells and the amount of surface-bound anxA5 depended on functional $\mathrm{Ca}^{2+}$-binding sites and was unaffected by the RGD motif (Figure 2c). Furthermore the $\mathrm{Ca}^{2+}$-chelator ethylenediaminetetraacetic acid (EDTA) prevented binding and dissociated bound RGD-anxA5 from the cell (data not shown). On the basis of these results we conclude that the T8D substitution changes anxA5 binding neither to PS embedded in a synthetic bilayer nor to PS in its natural environment of the plasma membrane of apoptotic cells. These results also indicate that the concave side of anxA5 is adjustable, allowing structural changes without interfering allosterically with the convex PS-binding side.
Integrin-binding in vitro. Next, accessibility and functionality of the RGD motif was investigated using phorbol 12-myristate 13-acetate (PMA)-stimulated human monocytic THP-1 cells, which upregulate integrin $\alpha \mathrm{v} \beta 3$ expression in response to phorbol esters. ${ }^{16}$ By using xCELLigence technology, PMA-induced adherence and spreading of THP-1 cells could be monitored over time (Supplementary Figure S1). On the basis of these analyses, 72-h stimulation with 50 nM PMA was chosen. RGD-anxA5-fluorescein but not RGT-anxA5-fluorescein bound to PMA-stimulated THP-1 cells (Figure 2d) in the presence of ethylene glycol tetraacetic acid (EGTA). Binding was performed in the presence of EGTA to avoid PS-dependent binding. EGTA conditions were chosen such that no dissociation of the $\alpha$ - and $\beta$-subunit of the integrin receptor occurred. ${ }^{17}$ Binding of RGD-M1234-fluorescein to THP-1 cells (Figure 2d) confirmed that the RGD motif mediated binding and not the $\mathrm{Ca}^{2+} / \mathrm{PS}$-binding sites. Similar results were found with MCF-7 cells expressing $\alpha \mathrm{v} \beta 5$ integrins $^{18}$ (data not shown). At physiological $\mathrm{Ca}^{2+}$ concentrations, the RGD motif causes extra binding to THP-1 cells on top of the PS-binding, as shown in Figure $2 e$. This extra binding is blocked by a 100-fold molar excess of cyclic Arg-Gly-Asp (cRGD) showing that RGD-anxA5 binds to integrins of THP-1 cells in the presence of $1 \mathrm{mM} \mathrm{Ca}^{2+}$.

RGD-anxA5 enhances efferocytosis by THP-1 macrophages in vitro. RGD-anxA5 stimulated efferocytosis by THP-1 macrophages with $40 \%$, whereas RGT-anxA5 inhibited it with $33 \%$ (Figure 3a) and lactadherin stimulates efferocytosis with $60 \%$ (data not shown) as measured with a recently described efferocytosis assay (Supplementary Figures S2A and B). ${ }^{13}$ This $40 \%$ stimulation can completely 


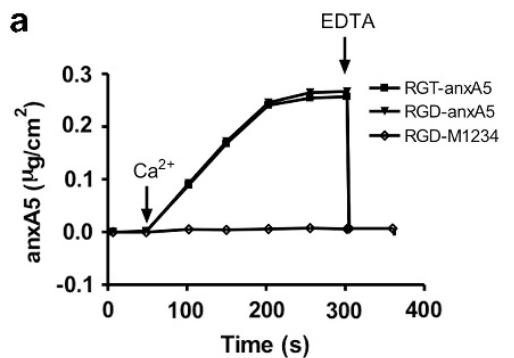

b
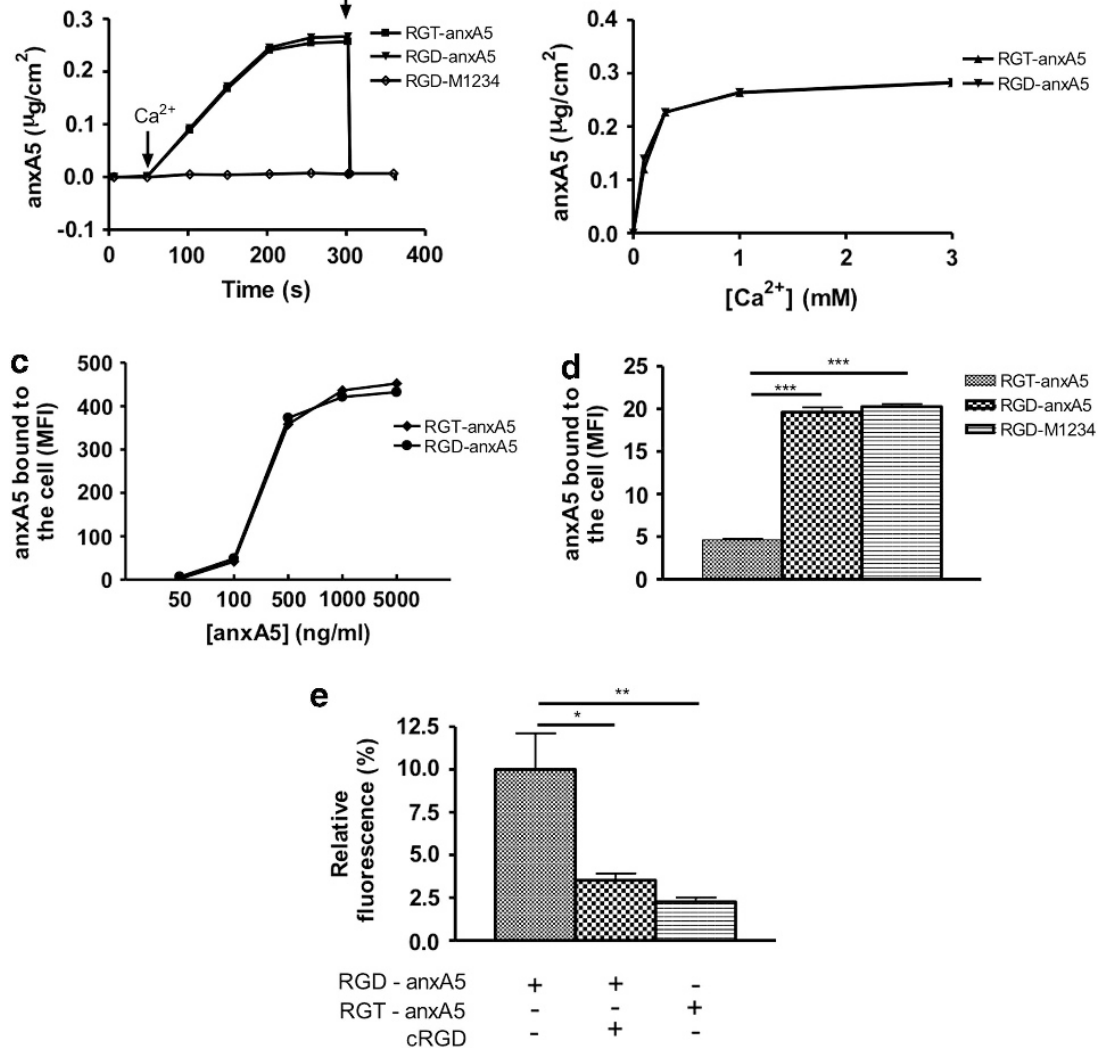

Figure 2 (a) Time courses of anxA5 variants $(1 \mu \mathrm{g} / \mathrm{ml})$ binding to a 20 mole\% DOPS/80 mole\% DOPC bilayer measured by ellipsometry. At the indicated time points (arrows) $3 \mathrm{mM} \mathrm{Ca}^{2+}$ and $6 \mathrm{mM}$ EDTA were added. (b) $\mathrm{Ca}^{2+}$-dependent binding curves for RGT-anxA5 (1 $\mu \mathrm{g} / \mathrm{ml}$ ) and RGD-anxA5 (1 $\left.\mu \mathrm{g} / \mathrm{ml}\right)$ to a $20 \mathrm{~mole} \% \mathrm{DOPS} / 80 \mathrm{~mole} \%$ DOPC bilayer. (c) Dose-response curve of fluorescein-labeled RGT-anxA5 and RGD-anxA5 binding to apoptotic Jurkat cells measured by flow cytometry. (d) Binding of $10 \mu \mathrm{g} / \mathrm{ml}$ fluorescein-labeled RGT-anxA5, RGD-anxA5 and RGD-M1234 to PMA-stimulated THP-1 cells $\left(1 \times 10^{6} \mathrm{cells} / \mathrm{ml}\right)$ in the presence of EGTA ( $\left.1 \mathrm{mM}\right)$. Mean \pm S.E.M. is shown. (e) Adherent THP-1 cells were incubated with fluorescein-labeled RGT-anxA5 and RGD-anxA5 $(10 \mu \mathrm{g} / \mathrm{ml})$ in $10 \mathrm{mM} \mathrm{HEPES} / \mathrm{pH} 7.4,150 \mathrm{mM} \mathrm{NaCl}, 5 \mathrm{mM} \mathrm{KCl}$, $1 \mathrm{mM} \mathrm{MgCl}_{2}$ and $1 \mathrm{mM} \mathrm{CaCl}_{2}$ in the absence and presence of CRGD $(28 \mu \mathrm{M})$ during 30 min. Cells were stained with 4,6-diamidino-2-phenylindole. Fluorescein was measured and number of cells were counted. Fluorescence was normalized for the number of cells. One, two and three asterisks represent $P$-values $<0.05,<0.01$ and $<0.001$, respectively

be inhibited by a 100-fold molar excess of cRGD (Figure 3b). Hence, introduction of RGD into the $\mathrm{N}$-terminal tail transformed anxA5 from an inhibitor into a stimulator of efferocytosis.

TNF $\alpha$ secretion during efferocytosis in vitro. TNF $\alpha$ secretion by PMA-stimulated THP-1 cells was slightly reduced by the presence of apoptotic cells either in the absence or presence of RGT-anxA5 and RGD-M1234 (Figure 3c). The combination of apoptotic cells and RGD-anxA5 dramatically increased secretion of TNF $\alpha$ (Figure 3c). None of the annexins affected the basal secretion of TNF $\alpha$ by PMAstimulated THP-1 cells in the absence of apoptotic cells (data not shown). These results indicate that RGD-anxA5 affects cytokine secretion only in the presence of apoptotic cells, likely by bridging between cell surface-expressed PS of the apoptotic cell and $\alpha_{v} \beta_{3}$ of the THP-1 cell, a property that is not possessed by RGT-anxA5 and RGD-M1234. Two-dimensional crystallization of RGD-anxA5 on the cell surface may contribute to enhanced outside-in signaling by integrin receptor clustering. ${ }^{19}$ The enhanced TNF $\alpha$ secretion presumably precludes a therapeutic role for RGD-anxA5.
However, PMA-stimulated THP-1 cells upregulate proinflammatory cytokines during efferocytosis ${ }^{20}$ in contrast to bloodderived macrophages, which suppress proinflammatory cytokine production when engulfing apoptotic cells. ${ }^{21}$ Therefore, we analyzed effects of apoptotic cells and annexins on upregulation of $\mathrm{TNF} \alpha \mathrm{mRNA}$ by bone marrow-derived macrophages (BMDM) that were differentiated into various phenotypes. Neither RGD-anxA5 nor RGT-anxA5 caused an upregulation of TNF $\alpha$-mRNA in any of the phenotypes studied (Figure 3d). These findings opened the door to in vivo studies.

PS-binding in vivo. Next, PS-binding in vivo was determined in a mouse model of ischemia/reperfusion injury of the heart. We showed previously that murine cardiomyocytes exposed to ischemic/reperfusion stress externalized and internalized PS continuously during a period of more than 60 min. $^{22}$ RGD-anxA5-fluorescein and RGT-anxA5alexa568 stained the same cardiomyocytes in the area at risk if administered intravenously (Figure 4). No uptake of RGD-anxA5 and RGT-anxA5 was observed in control mouse hearts (data not shown) and RGD-M1234 failed to 
a



b

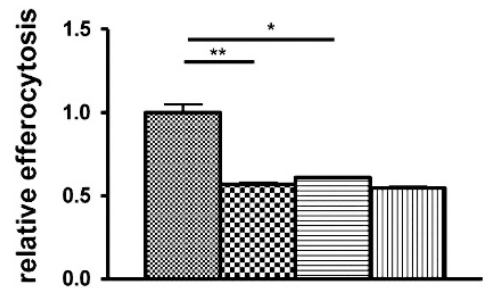

RGD - anxA5 RGT - anxA5 CRGD

c

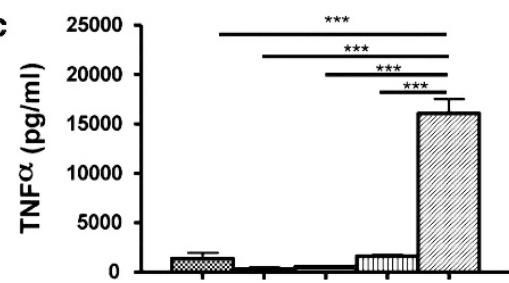

THP-1M $\phi$

apopt. cells

RGT - anxA5

RGD - M1234

RGD - anxA5
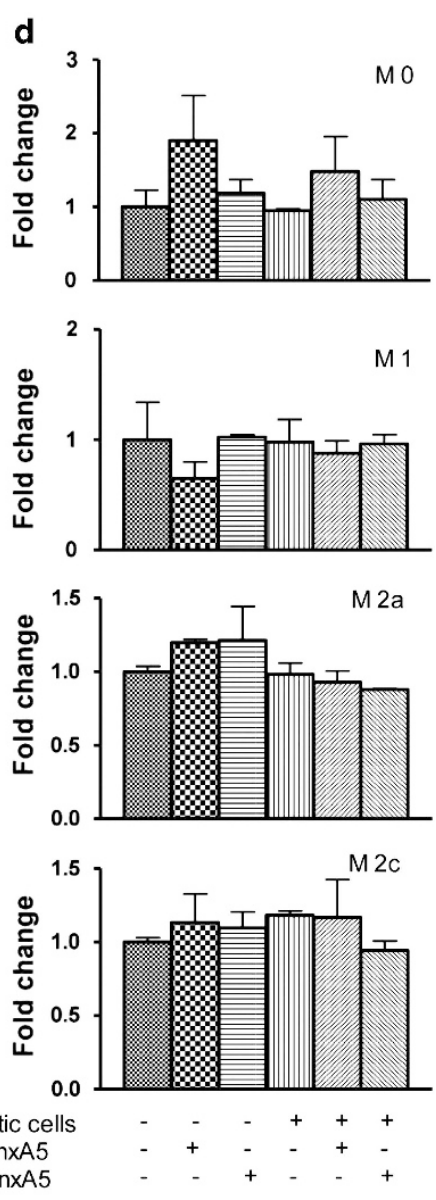

Figure 3 (a) Effects of anxA5 variants $(10 \mu \mathrm{g} / \mathrm{ml})$ on efferocytosis of apoptotic Jurkat cells $\left(2.5 \times 10^{6} \mathrm{cells} / \mathrm{ml}\right)$ by PMA-stimulated THP- 1 cells $\left(10^{6}\right.$ cells $\left./ \mathrm{ml}\right)$. (b) Effect of 100 -fold molar excess of CRGD on efferocytosis of apoptotic Jurkat cells $\left(2.5 \times 10^{6} \mathrm{cells} / \mathrm{ml}\right)$ by PMA-stimulated THP- 1 cells $\left(10^{6}\right.$ cells $\left./ \mathrm{ml}\right)$ in the presence of RGD-anxA5. (c) Effects of anxA5 variants $(10 \mu \mathrm{g} / \mathrm{ml})$ on TNF $\alpha$ secretion by PMA-stimulated THP-1 cells $\left(10^{6} \mathrm{cell} / \mathrm{s} / \mathrm{ml}\right)$ in the absence and presence of apoptotic Jurkat cells $\left(2.5 \times 10^{6}\right.$ cells $\left./ \mathrm{ml}\right)$. (d) Effects of anxA5 variants $(10 \mu \mathrm{g} / \mathrm{ml})$ on TNF $\alpha$ mRNA expression by M0, M1, M2a and M2C $\left(2.5 \times 10^{5} \mathrm{cell} / \mathrm{sell}\right)$ in the presence of apoptotic L929 cells $\left(6.3 \times 10^{5}\right.$ cells/ well). Mean \pm S.E.M. is shown. One, two and three asterisks represent $P$-values $<0.05,<0.01$ and $<0.001$, respectively
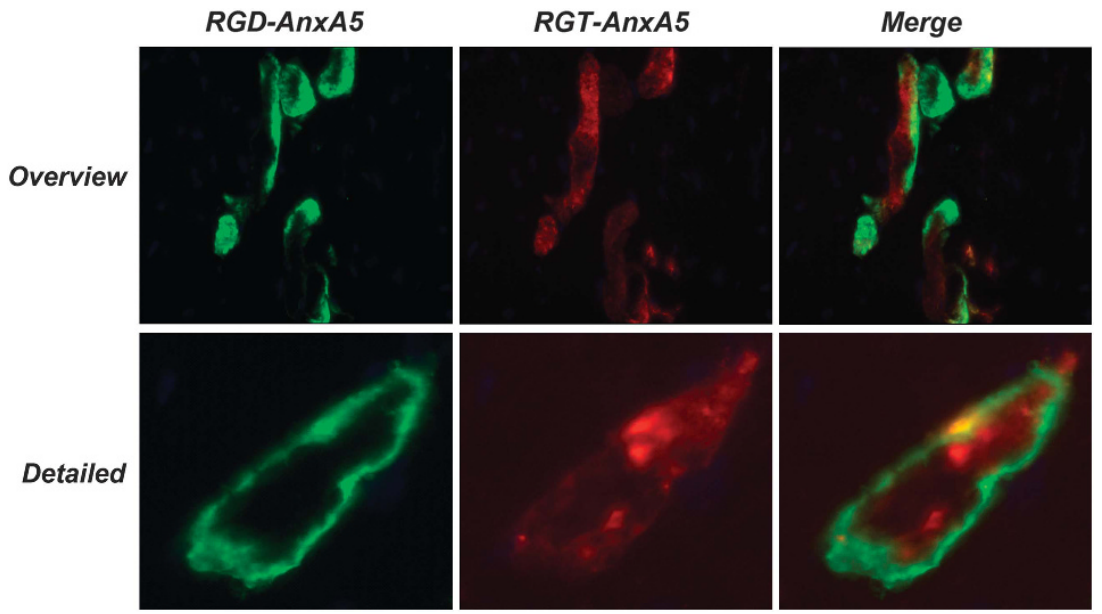

Figure 4 (a-c) Ex vivo images of sections of a mouse heart that was exposed to 30 min ischemia and $24 \mathrm{~h}$ of reperfusion. At the start of reperfusion RGT-anxA5-alexa568 (red, $70 \mu \mathrm{g}$ ) was injected intravenously. Twenty minutes before sacrifice RGD-anxA5-fluorescein (green, $70 \mu \mathrm{g}$ ) was injected intravenously. The heart was taken out, frozen, sectioned and analyzed by fluorescence microscopy. (d-f) A higher magnification image of the infarcted area showing a single stained cardiomyocyte 



Figure 5 Effects of anxA5 variants $(24 \mu \mathrm{g})$ on efferocytosis of CFSE-stained apoptotic neutrophils $\left(3.0 \times 10^{6} \mathrm{cells}\right)$ by resident peritoneal macrophages of C57BL/6J mice. (a) Collected peritoneal macrophages were analyzed by flow cytometry and relative phagocytosis was determined. Collected peritoneal macrophages were cultured during $20 \mathrm{~h}$ and TNF $\alpha$ (b) and IL-10 release (c) were quantified. Mean \pm S.E.M. is shown. One and two asterisks represent $P$-values $<0.05$ and $<0.01$, respectively

bind stressed cardiomyocytes (data not shown). These findings indicate that insertion of the RGD motif into the $\mathrm{N}$-terminal tail was without effect on the in vivo PS-target finding activity of anxA5.

RGD-anxA5 enhances efferocytosis in vivo. In order to assess the impact of RGD-anxA5 on efferocytosis, in vivo fluorescent apoptotic neutrophils were injected intraperitoneally into wild-type C57BL/6J mice. Resident peritoneal macrophages engulfed apoptotic neutrophils, a process that was quantified by flow cytometry (Supplementary Figure S2). RGD-anxA5 enhanced efferocytosis with $20 \%$, while RGT-anxA5 had no effect on phagocytosis (Figure 5a).

Cytokine release after efferocytosis in vivo. The effect of efferocytosis on cytokine production was determined by collecting peritoneal macrophages $30 \mathrm{~min}$ post-injection of apoptotic neutrophils in the absence or presence of annexins. Collected macrophages were cultured for $20 \mathrm{~h}$ and levels of secreted TNF $\alpha$ and IL-10 were measured in the culture medium. RGD-anxA5 induced an increase of cytokine secretion from 30 to $75 \mathrm{pg} / \mathrm{ml}$ (TNF $\alpha$, Figure $5 \mathrm{~b}$ ) and from 40 to $185 \mathrm{pg} / \mathrm{ml}$ (IL-10, Figure 5c). RGT-anxA5 did not alter cytokine secretion.

Endotoxin determination. All anxA5 variants contain less than one endotoxin units per milliliter.

\section{Discussion}

Enhancing phagocytosis has been proposed as therapeutic strategy to treat inflammation. ${ }^{4-6}$ Strategies could focus on the phagocyte and aim to stimulate the molecular machinery executing phagocytosis ${ }^{23}$ or focus on the phagocytic prey and label it with additional 'eat me' signals. ${ }^{24}$

Here we present the strategy to add additional 'eat me' signals to the apoptotic cell by targeting PS, which is a ubiquitous hallmark of apoptosis independent of cell type and cell death-inducing trigger. ${ }^{25}$ PS can interact directly or indirectly via PS-binding proteins with receptors on the phagocyte. ${ }^{9}$ The variety of engulfment receptors and apoptotic ligands led to the proposal of a 'tether and tickle' model, in which PS could mediate both tethering of the apoptotic cell to the phagocyte and tickling of the phagocyte by engaging different receptors. ${ }^{26}$ TIM-4, a member of the T-cell immunoglobulin and mucin family, was identified as a PS receptor mediating tethering. ${ }^{27,28}$ The integrin $\alpha_{\mathrm{v}} \beta_{3}$ acts as tickling receptor through binding $P S$ via the opsonin MFG-E8 ${ }^{29}$ and activating Rac1 and Rab5-dependent pathways. ${ }^{14}$ Both phagocytic receptors cooperate to engulf the PS-expressing apoptotic cell, ${ }^{14}$ indicating that apoptotic cell expresses sufficient PS to allow multiple interactions with different receptors and bridging molecules. Recently it was shown that $\alpha_{v} \beta_{3}$-dependent efferocytosis is a crucial process in dampening aggravation of chronic inflammation such as atherosclerosis. ${ }^{3}$ Therefore, we reasoned that targeting PS with 'eat me' signals engaging $\alpha_{\mathrm{v}} \beta_{3}$ could be a viable strategy to treat inflammation. We selected anxA5 as PS-targeting agent and modified it into an $\alpha_{\mathrm{v}} \beta_{3}$ ligand (RGD-anxA5) because of (i) the molecular imaging experience with anxA5, ${ }^{10}$ (ii) its elucidated three-dimensional structure ${ }^{30}$ and (iii) its property to form a two-dimensional network on the apoptotic cell surface, thereby clustering receptors with which it interacts. $^{31}$

In this paper we demonstrate that anxA5 can be successfully transformed from an inhibitor into a stimulator of efferocytosis. This was accomplished by a T8D substitution that introduces an RGD motif in the N-terminal tail, which is located at the concave surface of anxA5 apical to the convex side harboring the PS-binding sites. ${ }^{32}$ The T8D substitution had no deleterious effects on anxA5's PS-binding properties in vitro and its apoptotic cell targeting-function in vivo. In contrast to wild-type anxA5 (RGT-anxA5), RGD-anxA5 possessed the property of binding to $\alpha_{\mathrm{v}} \beta_{3}$ and $\alpha_{\mathrm{v}} \beta_{5}$-expressing cells and stimulating efferocytosis. The flexible loop conformation of the $\mathrm{N}$-terminal tail and the amino acids flanking the RGD motif likely facilitated ligation of the RGD motif with the integrin receptor. ${ }^{33} \mathrm{RGD}-\mathrm{anxA5}$ stimulated engulfment of apoptotic cells in vitro and in vivo. The latter was determined in a model that exposes resident peritoneal macrophages to apoptotic neutrophils. It is remarkable and promising that RGD-anxA5 was capable of stimulating efferocytosis by $20 \%$ in this system, as resident peritoneal macrophages already use TIM-4 for tethering and MFG-E8 to engage $\alpha_{\mathrm{v}} \beta_{3}$ for tickling. ${ }^{14}$

In addition to stimulating efferocytosis, RGD-anxA5 appeared to cause upregulation of TNF $\alpha$ in PMA-stimulated THP-1 cells. This would preclude RGD-anxA5 as a therapeutic agent, as a shift toward proinflammation aggravates inflammatory pathologies such as atherosclerosis. ${ }^{34} \mathrm{We}$ reasoned that RGD-anxA5-induced upregulation of $T N F \alpha$ could be a consequence of the in vitro model system we selected to study efferocytosis. It has been shown that $\alpha_{\mathrm{v}} \beta_{3}$ signaling augments TNF $\alpha$ production by PMA-stimulated THP-1 cells. ${ }^{35}$ In agreement with our reasoning we demonstrated that RGD-anxA5 was without noticeable effects on TNF $\alpha$ production by BMDMs of different phenotypes. Furthermore, RGD-anxA5 caused only a modest stimulation of TNF $\alpha$ 
production $(75 \mathrm{pg} / \mathrm{ml})$ in vivo by resident peritoneal macrophages that were exposed to apoptotic cells. Activated peritoneal macrophages can produce TNF $\alpha$ up to levels of several $1000 \mathrm{~s} \mathrm{pg/ml.}{ }^{36,37}$

Adequate efferocytosis is required for resolution of inflammation and suppression of progressive inflammation such as atherosclerosis. $^{34}$ It is generally accepted that adequate efferocytosis involves secretion of anti-inflammatory cytokines such as IL-10. ${ }^{2}$ PS-mediated tethering and tickling is intimately linked to efferocytosis and the secreted cytokine profile. Blocking PS with wild-type anA5 (RGT-anxA5) resulted in reduced efferocytosis and increased secretion of proinflammatory cytokines by activated peritoneal macrophages. ${ }^{12}$ Interestingly, we observed no effect of RGT-anxA5 on phagocytosis and cytokine secretion by resident macrophages, whereas RGD-anxA5 stimulated efferocytosis and enhanced $\mathrm{TNF} \alpha$ secretion \pm 2 -fold and IL-10 secretion \pm 4-fold. These results support the model that contribution of PS to efferocytosis depends on the macrophage population. ${ }^{38}$ Whether RGD-anxA5 exhibits therapeutic effects during inflammation is currently being investigated in a mouse model of atherosclerosis. We hypothesize that RDG-anxA5 protects against atherosclerosis because an RGD-dependent mechanism triggers $\mathrm{IL}-10$ release during efferocytosis, ${ }^{39}$ knock-out of the RGD-opsonin MFG-E8 culminates in reduced IL-10 levels and aggravation of atherosclerosis ${ }^{3}$ and intravenously administered anxA5 accumulates in atherosclerotic plaques. ${ }^{40}$

In conclusion, targeting cell surface-expressed PS to enhance efferocytosis is an attractive strategy for treatment of inflammatory diseases, and the rationally designed RGD-anxA5 is a promising therapeutic agent.

\section{Materials and Methods \\ Design, expression and purification of the different anxA5 variants. E. coli M15 (pREP4; Qiagen, Valencia, CA, USA) were transformed with PQE30Xa (Qiagen) containing CDNA of the anXA5 variants. Bacteria were grown to $0.8 \mathrm{OD} 600$ and expression was induced by adding $0.5 \mathrm{mM}$ isopropyl $\beta$-D-1-thiogalactopyrano-side (IPTG, Eurogentec, Seraing, Belgium). After $3 \mathrm{~h}$, bacteria were collected and resuspended in phosphate buffer $(20 \mathrm{mM}, \mathrm{pH} 7.4)$ containing $500 \mathrm{mM} \mathrm{NaCl}, 20 \mathrm{mM}$ imidazole and $1 \%$ Triton X-100. Bacteria were lysed by sonification at $12 \mu \mathrm{m}$ amplitude for $6 \times 10 \mathrm{~s}$. Lysis was continued at room temperature for $3 \mathrm{~h}$. Cell debris was removed by centrifugation. His-tagged proteins were isolated from supernatant by chromatography using nickel columns (GE Healthcare, Amersham, Buckinghamshire, UK) and an imidazole gradient. Figure 1 depicts an endotoxin-free RGD-anxA5 variant and a representative matrix-assisted laser desorption/ionization-time of flight/time of flight (MALDI-TOF/TOF) mass spectrometric analysis of a purified recombinantly expressed batch of this variant.}

Cell culture. THP-1 cells, a human monocytic cell line (American Type Culture Collection (ATCC), Manassas, VA, USA), were cultured in RPMI 1640 without indicator (Gibco-BRL, Invitrogen, Carlsbad, CA, USA) supplemented with $2 \mathrm{mM}$ glutamine (Gibco-BRL, Invitrogen), 10\% heat-inactivated fetal bovine serum (Gibco-BRL), 100 units $/ \mathrm{ml}$ penicillin (Gibco-BRL) and $100 \mu \mathrm{g} / \mathrm{ml}$ streptomycin (Gibco-BRL). Differentiation of THP-1 cells in adherent macrophages was achieved by addition of $50 \mathrm{nM}$ PMA (Promega, Madison, WI, USA) for $72 \mathrm{~h}$. PMAinduced adhesion and spreading was monitored real-time using xCELLigence apparatus (Roche, Almere, The Netherlands). The T-cell lymphoma Jurkat cell line (ATCC) was cultured in RPMI 1640 (Gibco-BRL) supplemented with $10 \%$ heatinactivated fetal bovine serum (Gibco-BRL), 100 units/ml penicillin (Gibco-BRL), $100 \mu \mathrm{g} / \mathrm{ml}$ streptomycin (GIBCO-BRL). L929 cells, a mouse fibroblast cell line (ATCC) were cultured in DMEM with high glucose (Gibco-BRL) supplemented with $10 \%$ heat-inactivated fetal bovine serum (Gibco-BRL), 100 units/ml penicillin (Gibco-BRL) and $100 \mu \mathrm{g} / \mathrm{ml}$ streptomycin (Gibco-BRL).
Bone marrow-derived macrophages isolation and differentiation. Bone marrow-derived macrophages isolation and differentiation were isolated as described by Goossens et al. ${ }^{41}$ After isolation, macrophages were stimulated with $10 \mathrm{U} / \mathrm{ml}$ mouse recombinant IFN $\gamma, 20 \mathrm{ng} / \mathrm{ml}$ mouse recombinant interleukin (IL)-4 or $10 \mathrm{ng} / \mathrm{ml}$ mouse recombinant IL-10 (to induce M1, M2a and M2c macrophages, respectively) or no cytokines (M0). After $24 \mathrm{~h}$ stimulation, macrophages were used in the efferocytosis assay.

Labeling of anxA5 variants with optical probes. RGD-anxA5 and RGT-anxA5 were labeled with maleimide-fluorescein (Pierce, Rockford, IL, USA) and maleimide-alexa568 (Invitrogen, Cergy Pontoise, France) while RGD-M1234 was labeled with fluorescein isothiocyanate (FITC, Invitrogen) according to the protocols of the manufacturers. FITC-labeled RGD-M1234 was purified by MonoQ ion exchange chromatography (Akta Explorer, GE Healthcare) to obtain 1:1 stoichiometric complexes. Stoichiometry of the complexes was verified with MALDI-TOF/TOF-analysis (Applied Biosystems, Foster City, CA, USA).

Ellipsometry. PS-binding characteristics of the anxA5 variants was determined by ellipsometry using a bilayer of $20 \mathrm{~mole} \%$ dioleoyl-phosphatidylserine/80 mole\% dioleoyl-phosphatidylcholine (20 mole\% DOPS/80 mole\% DOPC; Avanti Polar Lipids, Alabaster, AL, USA) as described previously. ${ }^{42}$

Binding to apoptotic Jurkat cells. Jurkat cells $\left(1 \times 10^{6} \mathrm{cell} / \mathrm{ml}\right)$ were triggered in culture medium to execute apoptosis by incubation with anti-Fas antibody (200 ng/ml clone 7C11, Beckman-Coulter, Marseille, France) for $3 \mathrm{~h}$. The course of apoptosis was determined by flow cytometry (Beckman-Coulter) using the anxA5-FITC staining protocol (Nexins Research, Kattendijke, The Netherlands). An aliquot of $25 \mu \mathrm{l}$ cell suspension was added to $220 \mu \mathrm{l}$ binding buffer ( $10 \mathrm{mM} \mathrm{HEPES} / \mathrm{NaOH}, \mathrm{pH} 7.4,150 \mathrm{mM} \mathrm{NaCl}, 5 \mathrm{mM} \mathrm{KCl}, 1 \mathrm{mM} \mathrm{MgCl}_{2}$ and $2.5 \mathrm{mM} \mathrm{CaCl}_{2}$ ) and $5 \mu$ with different concentrations of fluorescein-labeled anxA5.

Integrin-binding in vitro. Accessibility of the RGD motif for ligation with integrin receptors was determined by flow cytometry and fluorescence microscopy. By using flow cytometry, PMA-stimulated THP-1 cells were scraped and refreshed in complete RPMI 1640 (Gibco-BRL) at a concentration of $1 \times 10^{6} \mathrm{cells} / \mathrm{ml}$. An aliquot of $50 \mu \mathrm{l}$ of the cell suspension was added to $445 \mu \mathrm{l}$ EGTA-containing buffer (20 mM HEPES, $140 \mathrm{mM} \mathrm{NaCl}, 1 \mathrm{mM} \mathrm{EGTA}, \mathrm{pH}$ 7.4) and $5 \mu$ l fluorescein-labeled anxA5 variants solution $(200 \mu \mathrm{g} / \mathrm{ml})$. The assay was performed in EGTAcontaining buffer to chelate $\mathrm{Ca}^{2+}$-ions and prevent $\mathrm{Ca}^{2+}$-dependent PS-binding. After $30 \mathrm{~min}$ incubation at room temperature, binding of the variants to THP-1 macrophages was analyzed by flow cytometry. Results were calculated offline with WinMDI 2.8 software. By using fluorescence microscopy the binding of the RGD motif in the presence of physiological concentrations of $\mathrm{Ca}^{2+}$ was studied. Fluorescein-labeled RGT-anxA5 and RGD-anxA5 $(10 \mu \mathrm{g} / \mathrm{ml})$ were incubated for $30 \mathrm{~min}$ with the adherent THP-1 cells in $10 \mathrm{mM}$ HEPES/pH 7.4, $150 \mathrm{mM} \mathrm{NaCl}$, $5 \mathrm{mM} \mathrm{KCl}, 1 \mathrm{mM} \mathrm{MgCl}$ and $1 \mathrm{mM} \mathrm{CaCl} 2$ in the absence and in the presence of CRGD (100-fold molar excess). After nucleus staining, overview pictures were taken and fluorescence was quantified using Leica QWin software. Fluorescence was normalized for the number of cells.

Efferocytosis assay in vitro with THP-1 cells. Efferocytosis was quantified by flow cytometry as described. ${ }^{13}$ Briefly, THP-1 cells were differentiated with PMA to adherent macrophages as described. PMA-stimulated cells were washed twice with phosphate-buffered saline (PBS, Braun Melsungen, Germany). Jurkat cells were preincubated for $10 \mathrm{~min}$ with carboxyfluorescein succinimidyl ester (CFSE; Invitrogen) in serum-free RPMl 1640 medium, washed twice with PBS, refreshed in complete RPMI 1640 medium $\left(1 \times 10^{6} \mathrm{cells} / \mathrm{ml}\right)$ and treated with or without anti-Fas antibody $(200 \mathrm{ng} / \mathrm{ml}$ clone 7 C11). Apoptotic Jurkat cells were added to the differentiated THP-1 cells at a ratio $2.5: 1$ in the presence of anxA5 variant $(10 \mu \mathrm{g} / \mathrm{ml})$ and CRGD (100 times molar excess) if stated in the text. After $20 \mathrm{~h}$ of incubation, THP-1 macrophages were washed twice with PBS and collected with $0.5 \%$ trypsin/EDTA (Gibco-BRL). Efferocytosis of CFSE-Jurkat cells and subsequent processing in the phagolysosome induces a left shift of Fl-1 signal in the $\mathrm{Fl}-1$ versus $\mathrm{Fl}-3$ plot due to acidification of the phagolysosome (Supplementary Figure S2).

Two-photon laser scanning microscopy. Efferocytosis of apoptotic jurkat cells by differentiated THP-1 cells was visualized by two-photon laser scanning microscopy (TPLSM; as described previous by Douma et al. ${ }^{43}$ ). The procedure of cell treatment is identical to the flow cytometry protocol 
described above, with the exception that at the end of the incubation period THP-1 cells were fixed with $3.7 \%$ formaldehyde in PBS for $10 \mathrm{~min}$ at room temperature. Fixed THP-1 cells were stained with Phalloidin-Texas Red (Invitrogen) according to the protocol of the manufacturer.

xCELLigence cell adhesion assay. Cell adhesion and spreading of THP-1 cells were measured in 96-well plates with XCELLigence RTCA apparatus (Roche, Almere, The Netherlands) as described previously. ${ }^{44}$ Impedance is expressed in terms of a Cell Index $(\mathrm{Cl})$. $\mathrm{Cl}$ is a dimensionless value representing the impedance between sensing electrodes. Impedance changed by adhesion of cells to the surface and was monitored in time. Using this technique, we monitored adherence of 50000 THP-1 cells/well during differentiation with $50 \mathrm{nM}$ PMA

Efferocytosis assay in vitro with bone marrow-derived macrophages. After $24 \mathrm{~h}$ stimulation, macrophages were used in the efferocytosis assay. L929 were stimulated to undergo apoptosis with doxorubicin $(10 \mu \mathrm{M})$ overnight at a concentration of $2.0 \times 10^{6} \mathrm{cells} / \mathrm{ml}$. Apoptotic L929 cells were washed twice with PBS and added to M0-M1-M2a or M2c macrophages at a ratio $2.5: 1$ in the presence or absence of anxA5 variants $(10 \mu \mathrm{g} / \mathrm{ml})$. After $3 \mathrm{~h}$ of incubation, BMDM were washed twice with PBS and collected for mRNA isolation RNA was isolated with the High Pure RNA Isolation Kit (Roche, Basel, Switzerland). A quantity of $200 \mathrm{ng}$ total RNA was reverse transcribed using the iScript cDNA Synthesis Kit (Bio-Rad, Veenendaal, The Netherlands). Quantitative PCR was performed using $10 \mathrm{ng} \mathrm{CDNA}, 300 \mathrm{nM}$ of each primer, and IQ SYBR Green Supermix (Bio-Rad) in a total volume of $20 \mu$ l. Results are compared to each subtype without apoptotic Jurkat cells.

Ischemia/reperfusion of mouse heart in vivo. Induction of cardiac ischemia and subsequent reperfusion were performed as described previously. ${ }^{45}$ After left thoracotomy and exposure of the heart, the left anterior descending coronary artery was ligated for $30 \mathrm{~min}$ and subsequently reperfusion was established for $24 \mathrm{~h}$. At the start of reperfusion RGT-anxA5-alexa568 (red, $70 \mu \mathrm{g}$ ) was injected intravenously. Twenty minutes before sacrifice RGD-anxA5fluorescein (green, $70 \mu \mathrm{g}$ ) was injected intravenously. The heart was taken out, frozen, sectioned and analyzed by fluorescence microscopy (Leica DMRBE, Rijswijk, The Netherlands).

Efferocytosis assay in vivo. Efferocytosis was performed with apoptotic neutrophils in C57BL/6J mice (Charles River Laboratories, Wilmington, MA, USA) as described elsewhere. ${ }^{46}$ To study in vivo efferocytosis by resident peritoneal macrophages, mice were injected intraperitoneal (i.p.) with CFSE-labeled apoptotic human neutrophils $\left(3 \times 10^{6}\right.$ cells per mouse). Neutrophils were preincubated with the anxA5 variants (RGT-anXA5 and RGD-anxA5) for 5 min in buffer (20 mM HEPES, $140 \mathrm{mM} \mathrm{NaCl}, 1,8 \mathrm{mM} \mathrm{CaCl}_{2} \mathrm{pH}$ 7.4) before i.p. injection. Mice were sacrificed $30 \mathrm{~min}$ after i.p injection, and peritoneal cells were collected by lavage with $3 \mathrm{ml}$ of ice-cold PBS containing $3 \mathrm{mmol} / / \mathrm{EDTA}$ Efferocytosis was assessed by flow cytometry using a BD FACs Calibur platform (San Jose, CA, USA). After in vivo efferocytosis the macrophages were cultured in a 24-well plate and supernatant was taken for cytokine determination. To show the phagocytosis, the macrophages were stained with myeloperoxidase (MPO) according the protocols of the manufacturers to show the specificity of the assay (Supplementary Figure S2).

All animal experiments were approved by the local Animal Experimental Committee.

Cytokine analysis. Efferocytosis with THP-1 macrophages was performed as described above with the exception that the Jurkat cells were not stained with CFSE. After efferocytosis, supernatant was centrifuged at $300 \mathrm{~g}$ for $3 \mathrm{~min}$ to remove free Jurkat cells. Human tumor necrosis factor- $\alpha(\mathrm{TNF} \alpha)$-ELISA was performed as described elsewhere. ${ }^{47}$

Immunoreactive levels of murine IL-10 and TNF $\alpha$ (MCYTOMAG-70K-04) were measured in the supernatant of cultured peritoneal macrophages by using Milliplex mouse cytokines (Merck Millipore, Billerica, MA, USA). The samples were prepared according to the manufacturers' instructions and analyzed on Bio-Plex 200 Systems (Bio-Rad, Hercules, CA, USA).

Endotoxin determination. The endotoxin content was measured with the Endosafe PTS spectrophotometer using the Endosafe PTS cartridge (0.1 EU sensitivity, Charles River Laboratories).
Statistics. Statistics were performed by the non-parametric Mann-Whitney t-test.

One, two and three asterisks represent $P$-values $<0.05,<0.01$ and $<0.001$, respectively.

\section{Conflict of Interest}

The authors declare no conflict of interest.

Acknowledgements. This study is supported in part by the European Union grant Euregional PACT II from the Interreg IV program of Grensregio VlaanderenNederland (IVA-VLANED-1.20) and by project grants from the Fund for Scientific Research Flanders (FWO-Vlaanderen, G.0728.10, G067512N to DVK) and Methusalem grant (BOF09/01M00709 to PV) from the Flemish Government. DVK is a postdoctoral fellow paid by fellowship from FWO-Vlaanderen. We are indebted to Nicole Bitsch for her technical assistance and to Dr. Gerry Nicolaes (Department Biochemistry, Molecular Modeling and Structure Analysis, Maastricht University) for preparing Figures 1a and b. Lactadherin was obtained as a kind gift from Dr. J Rasmussen.

1. Krysko DV, D'Herde K, Vandenabeele P. Clearance of apoptotic and necrotic cells and its immunological consequences. Apoptosis 2006; 11: 1709-1726.

2. Savill J, Dransfield I, Gregory C, Haslett C. A blast from the past: clearance of apoptotic cells regulates immune responses. Nat Rev Immunol 2002; 2: 965-975.

3. Ait-Oufella H, Kinugawa K, Zoll J, Simon T, Boddaert J, Heeneman S et al. Lactadherin deficiency leads to apoptotic cell accumulation and accelerated atherosclerosis in mice. Circulation 2007; 115: 2168-2177.

4. Gaipl US, Beyer TD, Baumann I, Voll RE, Stach CM, Heyder P et al. Exposure of anionic phospholipids serves as anti-inflammatory and immunosuppressive signal - implications for antiphospholipid syndrome and systemic lupus erythematosus. Immunobiology 2003; 207: 73-81

5. Hanayama R, Tanaka M, Miyasaka K, Aozasa K, Koike M, Uchiyama Y et al. Autoimmune disease and impaired uptake of apoptotic cells in MFG-E8-deficient mice. Science 2004; 304: $1147-1150$.

6. Tabas I. Consequences and therapeutic implications of macrophage apoptosis in atherosclerosis: the importance of lesion stage and phagocytic efficiency. Arterioscler Thromb Vasc Biol 2005; 25: 2255-2264.

7. Nakanishi $Y$, Henson PM, Shiratsuchi A. Pattern recognition in phagocytic clearance of altered self. Adv Exp Med Biol 2009; 653: 129-138.

8. Fadok VA, Voelker DR, Campbell PA, Cohen JJ, Bratton DL, Henson PM. Exposure of phosphatidylserine on the surface of apoptotic lymphocytes triggers specific recognition and removal by macrophages. J Immunol 1992; 148: 2207-2216.

9. Ravichandran KS. Beginnings of a good apoptotic meal: the find-me and eat-me signaling pathways. Immunity 2011; 35: 445-455.

10. Boersma HH, Kietselaer BL, Stolk LM, Bennaghmouch A, Hofstra L, Narula J et al. Past, present, and future of annexin A5: from protein discovery to clinical applications. $J$ Nucl Med 2005; 46(12): 2035-2050.

11. Vermes I, Haanen C, Steffens-Nakken $H$, Reutelingsperger C. A novel assay for apoptosis. Flow cytometric detection of phosphatidylserine expression on early apoptotic cells using fluorescein labelled Annexin V. J Immunol Methods 1995; 184: 39-51.

12. Bondanza A, Zimmermann VS, Rovere-Querini P, Turnay J, Dumitriu IE, Stach CM et al. Inhibition of phosphatidylserine recognition heightens the immunogenicity of irradiated lymphoma cells in vivo. J Exp Med 2004; 200: 1157-1165.

13. Kenis H, van Genderen H, Deckers NM, Lux PA, Hofstra L, Narula J et al. Annexin A5 inhibits engulfment through internalization of PS-expressing cell membrane patches. Exp Cell Res 2006; 312: 719-726.

14. Toda S, Hanayama R, Nagata S. Two-step engulfment of apoptotic cells. Mol Cell Biol 2012; 32: 118-125.

15. Mira JP, Dubois T, Oudinet JP, Lukowski S, Russo-Marie F, Geny B. Inhibition of cytosolic phospholipase $A 2$ by annexin $V$ in differentiated permeabilized $H L-60$ cells. Evidence of crucial importance of domain I type $\| \mathrm{Ca}^{2+}$-binding site in the mechanism of inhibition. J Biol Chem 1997; 272: 10474-10482.

16. Prieto J, Eklund A, Patarroyo M. Regulated expression of integrins and other adhesion molecules during differentiation of monocytes into macrophages. Cell Immunol 1994; 156: 191-211.

17. Ma Y, Wong K. Reassociation and translocation of glycoprotein IIB-IIIA in EDTA-treated human platelets. Platelets 2007; 18: 451-459.

18. Andersen MH, Graversen H, Fedosov SN, Petersen TE, Rasmussen JT. Functional analyses of two cellular binding domains of bovine lactadherin. Biochemistry 2000; 39: 6200-6206.

19. Hato T, Pampori N, Shattil SJ. Complementary roles for receptor clustering and conformational change in the adhesive and signaling functions of integrin $\alpha$ llb $\beta 3$. J Cell Biol 1998; 141: 1685-1695. 
20. Kurosaka K, Watanabe N, Kobayashi Y. Production of proinflammatory cytokines by phorbol myristate acetate-treated THP-1 cells and monocyte-derived macrophages after phagocytosis of apoptotic CTLL-2 cells. J Immunol 1998; 161: 6245-6249.

21. Fadok VA, Bratton DL, Konowal A, Freed PW, Westcott JY, Henson PM. Macrophages that have ingested apoptotic cells in vitro inhibit proinflammatory cytokine production through autocrine/paracrine mechanisms involving TGF-beta, PGE2, and PAF. J Clin Invest 1998; 101: $890-898$

22. Kenis $H$, Zandbergen HR, Hofstra L, Petrov AD, Dumont EA, Blankenberg FD et al. Annexin a5 uptake in ischemic myocardium: demonstration of reversible phosphatidylserine externalization and feasibility of radionuclide imaging. J Nucl Med 2010; 51: 259-267.

23. Hodrea J, Majai G, Doro Z, Zahuczky G, Pap A, Rajnavolgyi E et al. The glucocorticoid dexamethasone programs human dendritic cells for enhanced phagocytosis of apoptotic neutrophils and inflammatory response. J Leukoc Biol 2011; 91: 127-136.

24. Chvanov M, Petersen OH, Tepikin AV. Pharmacologically directed cell disposal: labeling damaged cells for phagocytosis as a strategy against acute pancreatitis. Mol Interv 2010; 10: $80-85$.

25. Martin SJ, Reutelingsperger CP, McGahon AJ, Rader JA, van Schie RC, LaFace DM et al. Early redistribution of plasma membrane phosphatidylserine is a general feature of apoptosis regardless of the initiating stimulus: inhibition by overexpression of $\mathrm{Bcl}-2$ and $\mathrm{Abl}$. J Exp Med 1995; 182: 1545-1556.

26. Henson PM, Bratton DL, Fadok VA. The phosphatidylserine receptor: a crucial molecular switch? Nat Rev Mol Cell Biol 2001; 2: 627-633.

27. Miyanishi M, Tada K, Koike M, Uchiyama Y, Kitamura T, Nagata S. Identification of Tim4 as a phosphatidylserine receptor. Nature 2007; 450: 435-439.

28. Park D, Hochreiter-Hufford A, Ravichandran KS. The phosphatidylserine receptor TIM-4 does not mediate direct signaling. Curr Biol 2009; 19: 346-351.

29. Hanayama R, Tanaka M, Miwa K, Shinohara A, Iwamatsu A, Nagata S. Identification of a factor that links apoptotic cells to phagocytes. Nature 2002; 417: 182-187.

30. Huber R, Romisch J, Paques EP. The crystal and molecular structure of human annexin V, an anticoagulant protein that binds to calcium and membranes. EMBO J 1990; 9: $3867-3874$

31. Ungethum L, Kenis $H$, Nicolaes GA, Autin L, Stoilova-McPhie S, Reutelingsperger CP. Engineered annexin A5 variants with impaired cell entry for molecular imaging of apoptosis using pretargeting strategies. J Biol Chem 2011; 286: 1903-1910.

32. Huber R, Schneider M, Mayr I, Romisch J, Paques EP. The calcium binding sites in human annexin $\mathrm{V}$ by crystal structure analysis at $2.0 \mathrm{~A}$ resolution. Implications for membrane binding and calcium channel activity. FEBS Lett 1990; 275: 15-21.

33. Haubner R, Wester HJ, Reuning U, Senekowitsch-Schmidtke R, Diefenbach B, Kessler H et al. Radiolabeled alpha(v)beta3 integrin antagonists: a new class of tracers for tumor targeting. J Nucl Med 1999; 40: 1061-1071.
34. Van Vre EA, Ait-Oufella $\mathrm{H}$, Tedgui A, Mallat Z. Apoptotic cell death and efferocytosis in atherosclerosis. Arterioscler Thromb Vasc Biol 2012; 32: 887-893.

35. Kurihara $Y$, Nakahara T, Furue M. alphaVbeta3-integrin expression through ERK activation mediates cell attachment and is necessary for production of tumor necrosis factor- $\alpha$ in monocytic THP-1 cells stimulated by phorbol myristate acetate. Cell Immunol 2011; 270: 25-31.

36. Filardy AA, Pires DR, Nunes MP, Takiya CM, Freire-de-Lima CG, Ribeiro-Gomes FL et al. Proinflammatory clearance of apoptotic neutrophils induces an IL-12(low)IL-10(high) regulatory phenotype in macrophages. J Immunol 2010; 185: 2044-2050.

37. Michlewska S, Dransfield I, Megson IL, Rossi AG. Macrophage phagocytosis of apoptotic neutrophils is critically regulated by the opposing actions of pro-inflammatory and antiinflammatory agents: key role for TNF- $\alpha$. FASEB J 2009; 23: 844-854.

38. Fadok VA, Savill JS, Haslett C, Bratton DL, Doherty DE, Campbell PA et al. Different populations of macrophages use either the vitronectin receptor or the phosphatidylserine receptor to recognize and remove apoptotic cells. J Immunol 1992; 149: 4029-4035.

39. Asano K, Miwa M, Miwa K, Hanayama R, Nagase H, Nagata S et al. Masking of phosphatidylserine inhibits apoptotic cell engulfment and induces autoantibody production in mice. J Exp Med 2004; 200: 459-467.

40. Kietselaer BL, Reutelingsperger CP, Heidendal GA, Daemen MJ, Mess WH, Hofstra L et al. Noninvasive detection of plaque instability with use of radiolabeled annexin A5 in patients with carotid-artery atherosclerosis. N Engl J Med 2004; 350: 1472-1473.

41. Goossens P, Gijbels MJ, Zernecke A, Eijgelaar W, Vergouwe MN, van der Made I et al. Myeloid type I interferon signaling promotes atherosclerosis by stimulating macrophage recruitment to lesions. Cell Metab 2010; 12: 142-153.

42. Cuypers PA, Corsel JW, Janssen MP, Kop JM, Hermens WT, Hemker HC. The adsorption of prothrombin to phosphatidylserine multilayers quantitated by ellipsometry. J Biol Chem 1983; 258: 2426-2431.

43. Douma K, Megens RT, Reitsma S, Prinzen L, Slaaf DW, Van Zandvoort MA. Two-photon lifetime imaging of fluorescent probes in intact blood vessels: a window to sub-cellular structural information and binding status. Microsc Res Tech 2007; 70: 467-475.

44. Atienza JM, Yu N, Kirstein SL, Xi B, Wang X, Xu X et al. Dynamic and label-free cell-based assays using the real-time cell electronic sensing system. Assay Drug Dev Technol 2006; 4: 597-607.

45. Dumont EA, Reutelingsperger CP, Smits JF, Daemen MJ, Doevendans PA, Wellens HJ et al. Real-time imaging of apoptotic cell-membrane changes at the single-cell level in the beating murine heart. Nat Med 2001; 7: 1352-1355.

46. Montero-Melendez T, Patel HB, Seed M, Nielsen S, Jonassen TE, Perretti M. The melanocortin agonist AP214 exerts anti-inflammatory and proresolving properties. $A m \mathrm{~J}$ Pathol 2011; 179: 259-269.

47. Engelberts I, Moller A, Schoen GJ, van der Linden CJ, Buurman WA. Evaluation of measurement of human TNF in plasma by ELISA. Lymphokine Cytokine Res 1991; 10: 69-76.

Supplementary information accompanies the paper on Cell Death and Differentiation website (http://www.nature.com/cdd) 